\title{
Compensatory Lung Growth Occurs in Adult Dogs after Right Pneumonectomy
}

C. C. W. Hsia, L. F. Herazo, F. Fryder-Doffey, and E. R. Weibel

Department of Internal Medicine, University of Texas Southwestern Medical Center, Dallas, Texas 75235-9034; and Institute of

Anatomy, University of Bern, Bern, Switzerland

\begin{abstract}
We investigated the structural changes in the left lung of five adult male foxhounds $5 \mathrm{mo}(n=2)$ or $16 \mathrm{mo}(n=3)$ after right pneumonectomy ( $\sim 54 \%$ of lung resected) and five sex- and age-matched foxhounds 15-16 mo after right thoracotomy without pneumonectomy. Lungs were fixed by intratracheal instillation of glutaraldehyde and analyzed by standard morphometric techniques. After right pneumonectomy, volume of the left lung increased by $72 \%$. Volumes of all septal structures increased significantly and were more pronounced at 5 than at $16 \mathrm{mo}$ after pneumonectomy. At $16 \mathrm{mo}$, the relative increases in volume with respect to the control left lung were as follows: epithelium $73 \%$, interstitium $100 \%$, endothelium $55 \%$, and capillary blood volume $43 \%$. Surface areas of alveoli and capillary increased significantly by $52 \%$ and $34 \%$, respectively. At 5 mo after pneumonectomy, harmonic mean thickness of the tissueplasma barrier was significantly greater but at 16 mo it was not different from controls. There was a significant increase in diffusing capacity for oxygen (33\% above controls) at 16 mo after pneumonectomy. These data suggest that, in contrast to previous findings after left pneumonectomy, compensatory lung growth does occur in adult dogs after resection of $>50 \%$ of lung. ( $J$. Clin. Invest. 1994. 94:405-412.) Key words: pneumonectomy • lung resection • lung growth - morphometry • diffusing capacity for oxygen
\end{abstract}

\section{Introduction}

It is generally believed that postpneumonectomy compensatory lung growth occurs in immature dogs but not in fully mature dogs (1-3). In adult dogs, postpneumonectomy compensation is largely attributed to use of existing functional reserves in the remaining lung. These reports were based on findings in adult dogs after left pneumonectomy, equivalent to the removal of $\sim 42 \%$ of the lung. Our group has shown in adult foxhounds at $\sim 2 \mathrm{yr}$ after left pneumonectomy (3) that there was no significant increase in tissue volume of the remaining right lung compared with the right lung of normal dogs. However, there were marked changes in the existing structures of the remaining lung, including hyperinflation, enlargement of the alveolar

Address correspondence to Connie C. W. Hsia, M.D., Department of Internal Medicine, University of Texas Southwestern Medical Center, 5323 Harry Hines Boulevard, Dallas, TX 75235-9034.

Received for publication 10 November 1993 and in revised form 16 February 1994.

J. Clin. Invest.

(C) The American Society for Clinical Investigation, Inc.

0021-9738/94/07/0405/08 \$2.00

Volume 94, July 1994, 405-412 spaces, and thinning of the alveolar-capillary membrane. These structural changes were associated with a remarkable degree of functional compensation (4-6); no significant reduction in exercise capacity was found $1 \mathrm{yr}$ after left pneumonectomy compared with before. We expected that if the larger right lung is resected, functional reserves in the remaining lung would be smaller, and exercise limitation would become more apparent. Thus we performed a series of studies in adult foxhounds after right pneumonectomy and compared the results with those in matched sham-operated controls. To our surprise, we found that after right pneumonectomy, maximal oxygen uptake was only mildly reduced (by 14\%) (7); at a given exercise work load, alveolar-arterial oxygen tension gradient and mean pulmonary artery pressure at heavy exercise were lower than in dogs after left pneumonectomy (8). Thus the relative functional compensation, per unit of lung removed, was greater after right than after left pneumonectomy. These physiological data suggest that different sources of compensation may be involved after right pneumonectomy than after left pneumonectomy. In this paper we report the morphometric measurements performed on the remaining lung of these same dogs; our results demonstrate that structural adaptation is quantitatively and qualitatively different after right than after left pneumonectomy. Following the removal of the larger right lung, compensatory lung growth can occur even in adult dogs.

\section{Methods}

Animals. Surgical procedures have been described previously (4). 10 adult male pure bred foxhounds (2-4 yr of age at entry, 22-28 $\mathrm{kg}$ ) completed the study. Under general anesthesia, five dogs underwent right pneumonectomy through the right lateral 5th intercostal space ( $\mathrm{PNX}^{1}$ group); the other five dogs underwent right thoracotomy in the same fashion without pneumonectomy (SHAM group). Bilateral carotid artery loops were constructed. The dogs were trained to run freely on a motorized treadmill before surgery, and except for the immediate postoperative period, were kept exercise trained throughout the duration of the study. Two dogs from the pneumonectomy group died during the course of the study and were later replaced by two additional dogs. These two latter dogs had left ventricular catheters inserted at the time of pneumonectomy instead of bilateral carotid artery loops. Physiologic measurements of cardiopulmonary function at work loads up to maximal exercise are reported elsewhere (7-10). Animals were killed at about $5 \mathrm{mo}(n=2)$ or $16 \mathrm{mo}(n=3)$ after surgery in the pneumonectomy group, and at $16 \mathrm{mo}(n=5)$ after surgery in the SHAM group. All protocols were approved by the Institutional Review Board for Animal Research.

Lung fixation. The animal was deeply anesthetized with pentobarbital $(25 \mathrm{mg} / \mathrm{kg}$ i.v.), intubated via a tracheostomy, and placed in the supine position. The abdomen was opened through a midline incision and a small rent made in the diaphragm to collapse the right lung. An overdose of pentobarbital was given and the lung immediately reinflated

1. Abbreviations used in this paper: PNX, pneumonectomy; SHAM, thoracotomy without pneumonectomy. 
within the intact thorax by the intratracheal instillation of $2.5 \%$ glutaraldehyde buffered with potassium phosphate to a $\mathrm{pH} 7.40$ and an osmolarity $350 \operatorname{mosM}$ at a constant hydrostatic pressure of $25 \mathrm{cmH}_{2} \mathrm{O}$ above the highest point of the sternum. After the flow of fixatives into the lung had stopped, the endotracheal tube was tightly clamped. After 60 min of fixation in situ, the thorax was opened; the lung and heart were removed en bloc and completely submerged in $2.5 \%$ buffered glutaraldehyde.

Sampling procedures. The previously established four-level stratified sampling scheme (11) was employed: (level I) gross, (level II) low power light microscopic, (level III) high power light microscopic, and (level IV) electron microscopic analysis. The left and right lungs were each divided into an upper and a lower stratum. The right upper stratum consisted of the upper and middle lobes, the right lower stratum consisted of the lower and cardiac lobes. The left upper stratum consisted of the upper and lingular lobes which were sometimes incompletely separated; the left lower stratum consisted of the lower lobe. Each stratum was exhaustively sliced at 2 -cm intervals. Each slice was photographed using $35 \mathrm{~mm}$ Ektachrome color film for estimating lung volume and for estimating the volume density of coarse parenchyma in lung, $\mathrm{Vv}(\mathrm{cp}, \mathrm{L})$, by quantifying all structures measuring $>1 \mathrm{~mm}$ (level I). Tissue blocks were taken from each stratum by a systematic, volumeweighted sampling procedure (11). For the SHAM group, 2 blocks per stratum were taken for light microscopy (total of 8 blocks per dogs); and 4 blocks per stratum were taken for electron microscopy (total of 16 blocks per dog). For the pneumonectomy dogs, 3 blocks per stratum were taken for light microscopy (total of 6 blocks per dog); and 6 blocks per stratum were taken for electron microscopy (total of 12 blocks per dog). Samples from each block were embedded in methacrylate for thick sections $(5 \mu \mathrm{m})$ and stained with hematoxylin and eosin to estimate the volume density of fine-parenchyma in coarse parenchyma, $\mathrm{Vv}(\mathrm{fp}, \mathrm{cp})$, by quantifying all structures measuring between $20 \mu \mathrm{m}$ and $1 \mathrm{~mm}$ (level II, $\times 200$ ). Additional samples from each block were embedded in Epon. These were used for preparation of semithin sections $(1 \mu \mathrm{m})$ to estimate the volume density of alveolar septa in fine parenchyma under light microscopy, $\mathrm{Vv}(\mathrm{s}, \mathrm{fp})$, by quantifying structures measuring $<20 \mu \mathrm{m}$ (level III, $\times 400$ ), and to estimate volume and surface densities of alveolar structures within the septum, e.g., capillaries $\operatorname{Vv}(c, s)$, alveoli $\operatorname{Vv}(a, s)$, as well as harmonic mean thickness of the tissue-plasma diffusion barrier by electron microscopy (level IV, about $\times 11,000$ ). Details of these methods have been reported elsewhere (11).

Morphometric analysis. Using slides of the lung slices (level I), the volume of each stratum was estimated by the Cavalieri principle (12). Volume density of alveolar structures were determined by point counting and surface density of alveoli and capillaries by intersection counting. Under light microscopy (levels II and III), sufficient number of fields were examined to yield a total of 300-400 counted points or intersections per structure per stratum. For electron microscopy (level IV), the number of micrographs examined were 32 per stratum per dog for the SHAM group and 64 per stratum per dog for the PNX group. All morphometric data were calculated for each stratum separately; a volume-weighted average for the entire lung was then calculated. Absolute volume and surface area of individual alveolar structures were obtained by relating the respective volume and surface densities at each level back through the cascade of levels to the measured volume of the stratum (11).

Morphometric diffusing capacity for $\mathrm{O}_{2}\left(\mathrm{DL}_{\mathrm{O}_{2}}\right) . \mathrm{DL}_{\mathrm{O}_{2}}$ was estimated by a modified version (13) of the previously established morphometric model $(11,14)$. The model describes the gas diffusion path from alveolar air to the binding sites on hemoglobin as two serially linked conductance steps through the tissue and plasma barrier $\left(\mathrm{Db}_{\mathrm{O}_{2}}\right)$ and the erythrocyte $\left(\mathrm{De}_{\mathrm{O}_{2}}\right)$ :

$\mathrm{DL}_{\mathrm{O}_{2}}{ }^{-1}=\mathrm{Db}_{\mathrm{O}_{2}}{ }^{-1}+\mathrm{De}_{\mathrm{O}_{2}}{ }^{-1}$

where $\mathrm{Db}_{\mathrm{O}_{2}}=\mathrm{Kb}_{\mathrm{O}_{2}} \cdot \frac{\left(S_{\mathrm{a}}+S_{\mathrm{c}}\right)}{\left(2 \cdot \tau_{\mathrm{hb}}\right)}$

$\mathrm{De}_{\mathrm{O}_{2}}=\theta_{\mathrm{O}_{2}} \cdot V_{\mathrm{c}}$
$S_{\mathrm{a}}$ and $S_{\mathrm{c}}$ are the measured total alveolar and capillary surface area, and $V_{\mathrm{c}}$ the measured total capillary blood volume. $\tau_{\mathrm{hb}}$ is the harmonic mean thickness of the combined tissue and plasma barrier. $\mathrm{Kb}_{\mathrm{O}_{2}}$ is the Krogh diffusion coefficient for $\mathrm{O}_{2}$ in tissue and plasma taken from literature (15). The estimate of $\tau_{\mathrm{hb}}$ is normally distributed and since only the distances of random intercepts crossing both alveolar-capillary membrane and red cell membrane are measured, $\mathrm{Db}_{\mathrm{O}_{2}}$ in effect is an estimate of the conductance to $\mathrm{O}_{2}$ of that portion of the alveolar-capillary membrane in proximity to red cells. A detailed explanation of this modified model is presented elsewhere (13). $\theta_{\mathrm{O}_{2}}$ is the reaction rate of whole blood with $\mathrm{O}_{2}\left[\mathrm{in} \mathrm{ml} \cdot(\mathrm{ml} \cdot \mathrm{mmHg} \cdot \mathrm{s})^{-1}\right]$. We employed the same equation for calculating $\Theta_{\mathrm{O}_{2}}$ as used previously (15) in normal dogs,

$\Theta_{\mathrm{O}_{2}}=K_{\mathrm{c}(60 \%)}^{\prime} \cdot f(T) \cdot\left(0.0587 \cdot \alpha_{\mathrm{O}_{2}}\right) \cdot\left(1-S_{\mathrm{O}_{2}}\right) \cdot(0.01333 \cdot[\mathrm{Hb}])$

where $K_{\mathrm{c}(60 \%)}^{\prime}$ is the red cell reaction velocity at $60 \%$ saturation. The value of $K_{\mathrm{c}(60 \%)}^{\prime}=440 \mathrm{mM} \mathrm{m}^{-1} \cdot \mathrm{s}^{-1}$ is measured by the stop-flow technique and corrected for the effect of the unstirred layer of plasma surrounding the red cell $(16), f(T)$ is the temperature factor derived from the Arrhenius equation that corrects $K_{\mathrm{c}}^{\prime}$ from the standard $37^{\circ} \mathrm{C}$ to the core temperature measured at peak exercise workload. $\alpha_{\mathrm{O}_{2}}$ is the solubility of $\mathrm{O}_{2}$ at the core temperature during peak exercise workload. $\mathrm{S}_{\mathrm{O}_{2}}$ is the initial fractional saturation of $\mathrm{O}_{2}$. [Hb] is the hemoglobin concentration in grams per deciliter of blood measured at heavy exercise.

Data analysis. Results were expressed as either mean \pm range or mean \pm SEM. Data from the PNX dogs at 6 and 15 mo were analyzed separately. Volume and surface densities in the remaining lung of PNX animals were compared with those in the left lung of SHAM animals by one factor analysis of variance using STATVIEW (v.4.0). Absolute volumes, surface areas and diffusing capacities were compared to those in the left lung and both lungs of SHAM animals. Differences among groups at a $P$ value of less than 0.05 were considered significant.

\section{Results}

Table I shows that there was no difference in body weight among groups. The right lung in the SHAM group constituted $54.2 \pm 1.0 \%$ (mean \pm SEM) of total lung volume. Volumes of the left lung were similar at 5 and 16 mo after pneumonectomy and increased by $72 \%$ compared with controls. Total lung volume was not different between the two pneumonectomy groups but was significantly lower than that of both lungs in the SHAM group. Morphometric hematocrit was significantly lower in the dogs 5 mo after pneumonectomy but normal in the group 16 mo after pneumonectomy. As a result, $\boldsymbol{\theta}_{\mathrm{O}_{2}}$ was lower at 5 mo after pneumonectomy. The septum was thicker than normal at 5 but not at 16 mo after pneumonectomy. Harmonic mean thickness of the combined tissue-plasma barrier was significantly elevated at 5 mo but decreased to normal by 16 mo after pneumonectomy.

Volume densities in the left lung are shown in Table II. Volume density of fine parenchyma in lung was lower 5 mo after pneumonectomy than in controls. Volume densities of tissue components within the septum were increased at 5 mo after pneumonectomy but was similar to controls by 16 mo after pneumonectomy. Volume density of capillaries within the septum was lower than normal at 5 mo but increased significantly by 16 mo after pneumonectomy. Surface-to-volume ratios of alveoli, $\operatorname{Sv}(\mathrm{a}, \mathrm{s})$, and capillaries, $\operatorname{Sv}(\mathrm{c}, \mathrm{s})$, within the septum are also shown in Table II; both indices were lower than controls at 5 mo but similar to controls by 16 mo after pneumonectomy. $\mathrm{Sv}(\mathrm{c}, \mathrm{s})$ also increased between 5 and 16 mo after pneumonectomy. The average ratio of alveolar surface area to lung volume, $\mathrm{Sv}(\mathrm{a}, \mathrm{L})$, was slightly lower in PNX dogs but the difference did not achieve statistical significance. 


\begin{tabular}{|c|c|c|c|c|}
\hline & \multicolumn{2}{|c|}{ Right PNX* 5 mo } & \multirow{2}{*}{$\frac{\text { Right } \mathrm{PNX}^{\ddagger} 16 \mathrm{mo}}{3}$} & \multirow{2}{*}{$\frac{\text { SHAM }^{\ddagger}}{5}$} \\
\hline Number & & 2 & & \\
\hline Body weight (kg) & 26.4 & $(25.2,27.5)$ & $24.3 \pm 0.6$ & $26.0 \pm 1.2$ \\
\hline Left lung volume (ml/kg) & $41.6^{8}$ & $(38.5,44.7)$ & $43.4 \pm 4.0^{8}$ & $24.9 \pm 0.8$ \\
\hline Total lung volume $(\mathrm{ml} / \mathrm{kg})$ & $41.6^{8}$ & $(38.5,44.7)$ & $43.4 \pm 4.0^{8}$ & $54.3 \pm 1.3$ \\
\hline Morphometric hematocrit (\%) & $0.32^{8 \|}$ & $(0.30,0.33)$ & $0.49 \pm 0.01^{8}$ & $0.52 \pm 0.03$ \\
\hline$\Theta_{\mathrm{O}_{2}}\left(\mathrm{ml} \cdot[\mathrm{ml} \cdot \mathrm{s} \cdot \mathrm{mmHg}]^{-1}\right)$ & $0.055^{\S \|}$ & $(0.054,0.056)$ & $0.066 \pm 0.000$ & $0.062 \pm 0.001$ \\
\hline Mean septal thickness $(\mu \mathrm{m})$ & $5.89^{8 \|}$ & $(5.77,6.00)$ & $4.92 \pm 0.18$ & $4.79 \pm 0.31$ \\
\hline$\tau_{\mathrm{hb}}(\mu \mathrm{m})$ & $1.32^{8 \|}$ & $(1.29,1.34)$ & $0.93 \pm 0.03$ & $0.78 \pm 0.04$ \\
\hline
\end{tabular}

* Values are means with ranges in parentheses. ${ }^{\ddagger}$ Values are mean \pm SEM. ${ }^{8} P<0.05$ vs. SHAM left lung. $\quad \| P<0.05$ vs. right PNX 16 mo.

Qualitative appearance of the lung under light microscopy is illustrated in Fig. 1. At 5 mo after right pneumonectomy (Fig. $1 \mathrm{~b})$, the septum was appreciably thicker than in the SHAM animals (Fig. 1 a). At 16 mo after right pneumonectomy (Fig. $1 c$ ), the alveolar spaces and mean septal thickness were normal. The alveolar enlargement previously reported in adult dogs after left pneumonectomy (3) was less evident in dogs after right pneumonectomy, either at 5 or $16 \mathrm{mo}$.

Absolute volumes of all septal structures of the left lung increased significantly at both time points after pneumonectomy (Table III) compared with SHAM animals; the increases were consistently greater at 5 than at $16 \mathrm{mo}$. By 16 mo after pneumonectomy, total septal volume increased by $59 \%$, septal tissue volume by $81 \%$, and capillary blood volume by $43 \%$ over control values in the left lung. Volumes of both type I and type II epithelium increased; total epithelial cell volume increased by $73 \%$. Volume of interstitium increased by $100 \%$ and volume of endothelium increased by $55 \%$. Alveolar surface area increased by $52 \%$ and capillary surface area increased by $34 \%$. There was a slight but statistically insignificant increase in alve- olar and capillary surface areas between 5 and 16 mo after pneumonectomy.

The components of $\mathrm{DL}_{\mathrm{O}_{2}}$ are shown in Table IV. At 5 mo after pneumonectomy, $\mathrm{De}_{\mathrm{O}_{2}}, \mathrm{Db}_{\mathrm{O}_{2}}$ and $\mathrm{DL}_{\mathrm{O}_{2}}$ were not different from controls. By $16 \mathrm{mo}$ after pneumonectomy, $\mathrm{De}_{\mathrm{O}_{2}}$ and $\mathrm{DL}_{\mathrm{O}_{2}}$ had increased significantly (52\% and $33 \%$, respectively). $\mathrm{Db}_{\mathrm{O}_{2}}$ was also higher (25\%) than normal, but the difference did not achieve statistical significance.

\section{Discussion}

Summary of results. In these dogs, right pneumonectomy was equivalent to the resection of $54.2 \%$ of lung. At 5 mo after right pneumonectomy, structural changes in the remaining lung were marked by thickening of the septum as well as hypertrophy and/or hyperplasia of the septal tissue compartments. At 16 mo after right pneumonectomy, structural changes were marked by a normal septal thickness, largely normal volume and surface densities of alveolar compartments, less pronounced but persistently significant increases in absolute volumes of septal struc-

Table II. Volume and Surface Densities of Septal Structures

\begin{tabular}{|c|c|c|c|c|}
\hline & Right $\mathrm{F}$ & $\mathrm{PNX}^{*} 5 \mathrm{mo}$ & Right PNS ${ }^{\ddagger} 16$ mo & SHAM $^{\ddagger}$ left lung \\
\hline \multicolumn{5}{|l|}{ Volume density in lung } \\
\hline Coarse parenchyma, Vv(cp, L) & 0.924 & $(0.923,0.925)$ & $0.923 \pm 0.003$ & $0.928 \pm 0.004$ \\
\hline Fine parenchyma, $V v(f p, L)$ & $0.797^{8}$ & $(0.795,0.798)$ & $0.814 \pm 0.007$ & $0.829 \pm 0.008$ \\
\hline Septum, Vv(s, L) & 0.120 & $(0.116,0.124)$ & $0.103 \pm 0.011$ & $0.112 \pm 0.004$ \\
\hline \multicolumn{5}{|l|}{ Volume density in septum } \\
\hline Type I epithelium, Vv(epi I, s) & 0.104 & $(0.101,0.107)$ & $0.103 \pm 0.003$ & $0.108 \pm 0.011$ \\
\hline Type II epithelium, Vv(epi II, s) & 0.055 & $(0.054,0.057)$ & $0.043 \pm 0.003$ & $0.034 \pm 0.015$ \\
\hline Total epithelium, Vv(epi, s) & 0.160 & $(0.155,0.164)$ & $0.153 \pm 0.003$ & $0.142 \pm 0.017$ \\
\hline Interstitium, Vv(int, s) & $0.305^{811}$ & $(0.300,0.311)$ & $0.230 \pm 0.006$ & $0.180 \pm 0.005$ \\
\hline Endothelium, Vv(endo, s) & 0.112 & $(0.102,0.121)$ & $0.097 \pm 0.003$ & $0.100 \pm 0.004$ \\
\hline Tissue, Vv(tissue, $\mathrm{s}$ ) & $0.576^{8 \|}$ & $(0.576,0.576)$ & $0.473 \pm 0.007$ & $0.420 \pm 0.021$ \\
\hline Capillary, Vv(c, s) & $0.424^{\S 11}$ & $(0.424,0.424)$ & $0.527 \pm 0.007$ & $0.580 \pm 0.021$ \\
\hline \multicolumn{5}{|l|}{ Surface density in septum $\left(\mathrm{cm}^{-1}\right)$} \\
\hline Alveoli, $\operatorname{Sv}(a, s)$ & $3413^{8}$ & $(3333,3493)$ & $4082 \pm 146$ & $4278 \pm 304$ \\
\hline Capillary, Sv(c, s) & $2208^{8 \|}$ & $(2157,2259)$ & $2825 \pm 105^{8}$ & $3345 \pm 215$ \\
\hline \multicolumn{5}{|l|}{ Surface density in lung $\left(\mathrm{cm}^{-1}\right)$} \\
\hline Alveoli, Sv(a, L) & 410 & $(386,435)$ & $417 \pm 30$ & $474 \pm 20$ \\
\hline Capillary, Sv(c, L) & $266^{8}$ & $(250,281)$ & $289 \pm 20^{8}$ & $371 \pm 15$ \\
\hline
\end{tabular}

* Values are means with ranges in parentheses. ${ }^{\ddagger}$ Values are means \pm SEM. ${ }^{\S} P<0.05$ vs. SHAM left lung. $\quad$ " $P<0.05$ vs. right PNX 16 mo. 

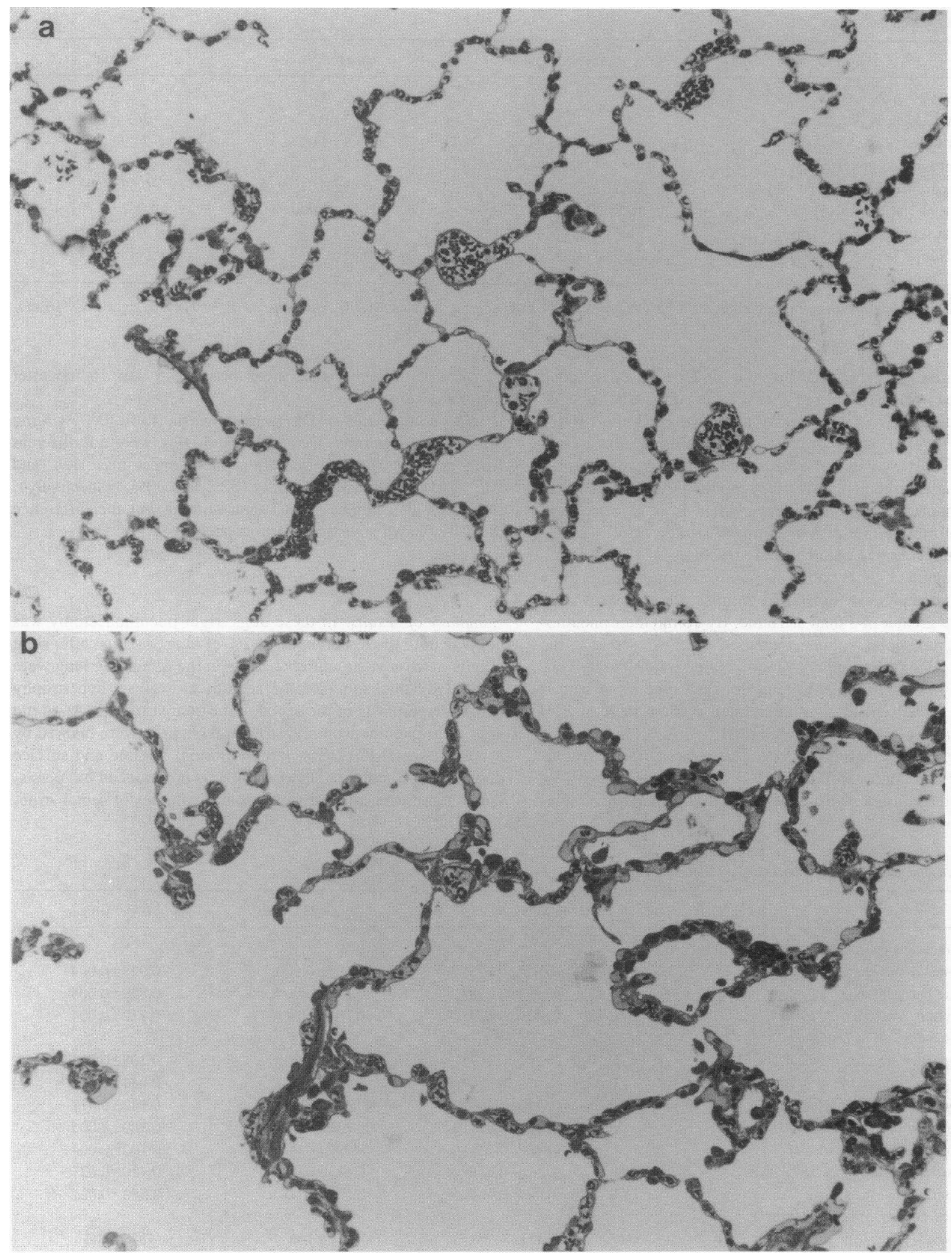

Figure 1. Representative light micrographs of the lung $\times 500$. (a) Left lung of a dog in SHAM group. (b) Left lung of a dog 5 mo after right pneumonectomy. $(c)$ Left lung of a dog 16 mo after right pneumonectomy. 


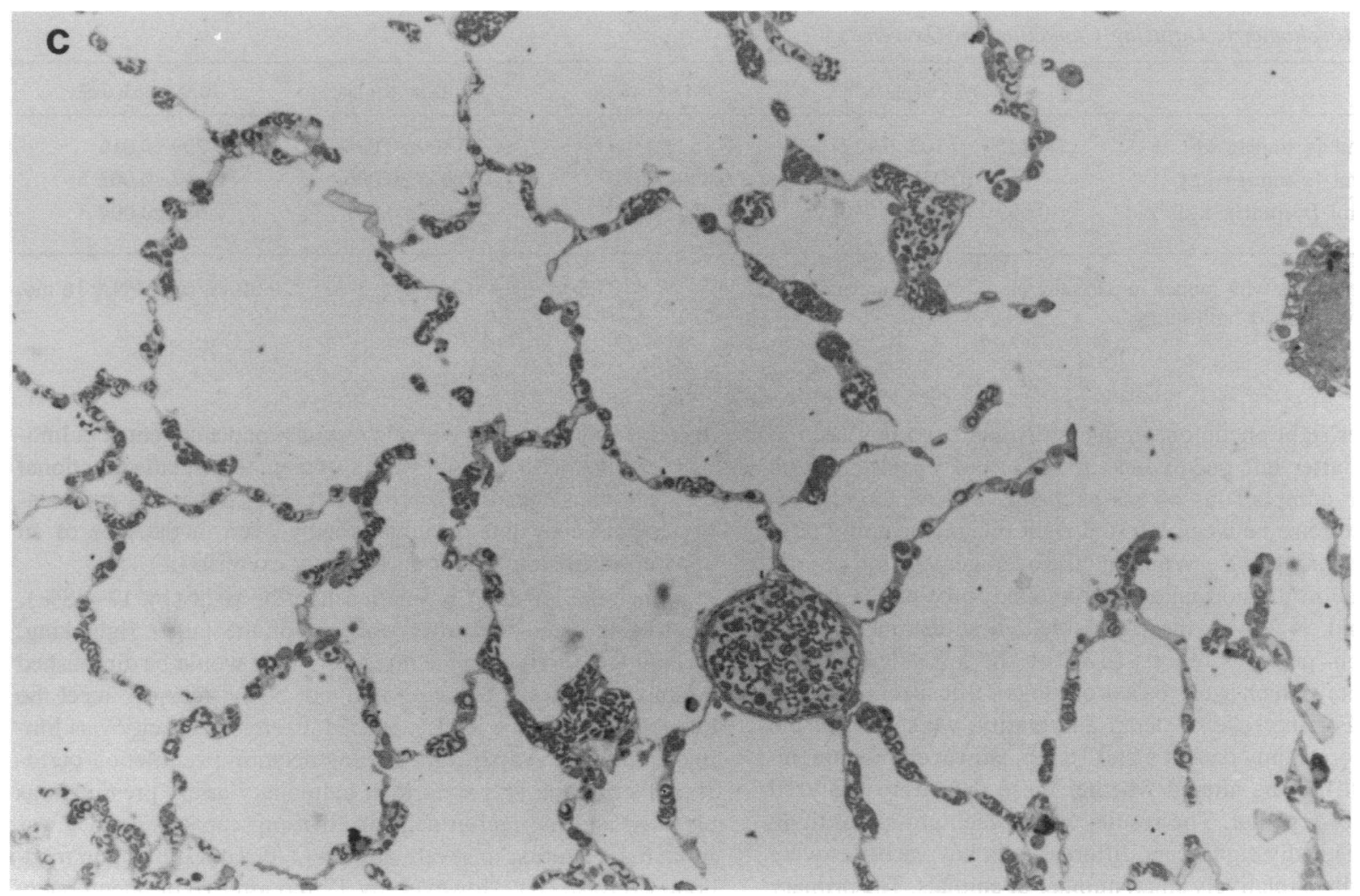

Figure 1.Continued.

tures as well as progressively higher total surface areas of alveoli and capillaries compared with the group 5 mo after pneumonectomy. Compensation in lung volume was significant but incomplete at both time points. The ratio of alveolar surface area to volume was similar in all groups, indicating that the increase in lung volume was associated with an increased complexity of the septa. In dogs 5 mo after pneumonectomy, the greater septal tissue thickness and lower hematocrit led to a greater diffusion resistance for oxygen across the tissue-plasma barrier and prevented a significant increase in $\mathrm{DL}_{\mathrm{O}_{2}}$. In dogs 16 mo after pneumonectomy, septal tissue thickness and hematocrit were normal and $\mathrm{DL}_{\mathrm{O}_{2}}$ was significantly higher. These results suggest a vigorous and sustained cellular response to right pneumonectomy that is marked by initial tissue proliferation followed by structural remodeling. These structural changes follow a time course more protracted than previously recognized; eventually they result in a significant compensatory increase in gas exchange capacity of the remaining lung. The structural re-

Table III. Absolute Volumes and Surface Areas of Septal Structures

\begin{tabular}{|c|c|c|c|c|}
\hline & Right PNX* 5 mo & Right PNX $^{\ddagger} 16$ mo & SHAM $^{\ddagger}$ left lung & SHAM $^{\ddagger}$ both lungs \\
\hline \multicolumn{5}{|l|}{ Volume $(\mathrm{ml} / \mathrm{kg})$} \\
\hline Type I epithelium & $0.52^{8 \|}(0.48,0.55)$ & $0.46 \pm 0.03^{8 \|}$ & $0.29 \pm 0.02$ & $0.63 \pm 0.03$ \\
\hline Type II epithelium & $0.28^{8} \quad(0.26,0.30)$ & $0.21 \pm 0.02$ & $0.10 \pm 0.05$ & $0.19 \pm 0.06$ \\
\hline Total epithelium & $0.80^{8} \quad(0.74,0.85)$ & $0.67 \pm 0.05^{8}$ & $0.39 \pm 0.05$ & $0.81 \pm 0.07$ \\
\hline Interstitium & $1.52^{8 \| 1}(1.44,1.61)$ & $1.01 \pm 0.05^{8}$ & $0.50 \pm 0.02$ & $1.20 \pm 0.06$ \\
\hline Endothelium & $0.55^{81} \quad(0.53,0.58)$ & $0.42 \pm 0.02^{811}$ & $0.27 \pm 0.00$ & $0.58 \pm 0.03$ \\
\hline Septum & $5.00^{8 \|}(4.8,5.20)$ & $4.41 \pm 0.27^{811}$ & $2.78 \pm 0.11$ & $5.97 \pm 0.27$ \\
\hline Tissue & $2.87^{81}(2.76,2.98)$ & $2.09 \pm 0.12^{811}$ & $1.16 \pm 0.06$ & $2.59 \pm 0.13$ \\
\hline Capillaries & $2.11^{\| \prime} \quad(2.03,2.20)$ & $2.31 \pm 0.16^{811}$ & $1.62 \pm 0.10$ & $3.39 \pm 0.25$ \\
\hline \multicolumn{5}{|l|}{ Surface area $\left(\mathrm{m}^{2} / \mathrm{kg}\right)$} \\
\hline Alveoli & $1.70^{8 \|} \quad(1.67,1.73)$ & $1.80 \pm 0.08^{8 \|}$ & $1.18 \pm 0.05$ & $2.49 \pm 0.08$ \\
\hline Capillaries & $1.10^{\| \prime} \quad(1.08,1.12)$ & $1.24 \pm 0.06^{8 \|}$ & $0.92 \pm 0.04$ & $1.92 \pm 0.06$ \\
\hline
\end{tabular}

${ }^{*}$ Values are means with ranges in parentheses. ${ }^{\ddagger}$ Values are means \pm SEM. ${ }^{\S} P<0.05$ vs. SHAM left lung. ${ }^{1} P<0.05$ vs. right PNX 16 mo. $\| P<0.05$ vs. SHAM both lungs. 


\begin{tabular}{|c|c|c|c|c|}
\hline & R PNX* 5 mo & R PNX ${ }^{\ddagger} 16$ mo & SHAM ${ }^{\ddagger}$ left lung & SHAM $^{\ddagger}$ both lungs \\
\hline $\mathrm{De}_{\mathrm{O}_{2}}\left(\mathrm{ml} \cdot[\mathrm{s} \cdot \mathrm{mmHg} \cdot \mathrm{kg}]^{-1}\right)$ & $0.115^{8}(0.107,0.122)$ & $0.152 \pm 0.011^{8 \|}$ & $0.100 \pm 0.006$ & $0.209 \pm 0.016$ \\
\hline $\mathrm{Db}_{\mathrm{O}_{2}}\left(\mathrm{ml} \cdot[\mathrm{s} \cdot \mathrm{mmHg} \cdot \mathrm{kg}]^{-1}\right)$ & $0.059^{34}(0.059,0.059)$ & $0.090 \pm 0.005^{8}$ & $0.075 \pm 0.006$ & $0.154 \pm 0.003$ \\
\hline $\mathrm{DL}_{\mathrm{O}_{2}}\left(\mathrm{ml} \cdot[\mathrm{s} \cdot \mathrm{mmHg} \cdot \mathrm{kg}]^{-1}\right)$ & $0.039^{54}(0.038,0.040)$ & $0.056 \pm 0.003^{8 \|}$ & $0.042 \pm 0.001$ & $0.088 \pm 0.004$ \\
\hline
\end{tabular}

* Values are means with ranges in parentheses. ${ }^{\ddagger}$ Values are means \pm SEM. $\| P<0.05$ vs. SHAM left lung. $\quad$ ' $P<0.05$ vs. right PNX 16 mo. ${ }^{8} P<0.05$ vs. SHAM both lungs.

sponse after right pneumonectomy is distinct from that seen in adult dogs after left pneumonectomy (3) and consistent with physiologic comparisons of gas exchange and hemodynamics at heavy exercise between left and right pneumonectomy (8).

Critique of methods. We found the average partition of total lung volume in the normal adult foxhound to be $45.8 \%$ on the left side and $54.2 \%$ on the right side. These estimates differ slightly from previous reports (42\% on the left side and $58 \%$ on the right), which were based on dogs of unspecified breed (17-19). For the sake of detail and clarity, we separated the postpneumonectomy data at 5 and 16 mo. However, our conclusions would not be altered whether these data were analyzed separately or together. The results within each group are tight, so that statistically significant differences in key variables were achieved with a relatively small number of animals. The primary morphometric results in the present SHAM animals are generally in agreement with those previously reported in three normal mongrel dogs (15); the latter were used as control data in our previous paper addressing the structural changes after left pneumonectomy (3). Volume and surface densities of alveolar structures between these two studies agree closely (within 3\%); total surface areas of alveoli and septum agree to within $4 \%$. However, methodological differences preclude direct comparison of other measurements. In the previous studies, lung volume was estimated by water displacement; in the present study it was estimated by the Cavalieri principle, which gives a slightly lower value. Consequently the absolute volumes of septum, tissue and capillary (per $\mathrm{kg}$ of body wt) are $10 \%$ to $15 \%$ lower in the present study. Membrane diffusing capacity in this study was estimated using a recent modification of the original model proposed by Weibel; the revised model yields an estimate of $\mathrm{DL}_{\mathrm{O}_{2}} \sim 20 \%$ lower than the original model (13).

Comparison of physiologic compensation after left and right pneumonectomy in adult dogs. Previous studies have suggested that the potential for postpneumonectomy compensatory lung growth is limited in fully mature dogs. Davies et al. (2) found no significant increase in septal tissue volume or number of alveoli in the remaining lung of adult dogs $5 \mathrm{yr}$ after left pneumonectomy compared with the right lung of unoperated controls. A more recent report from our laboratory (3) also found no evidence of compensatory structural lung growth in adult foxhounds 2 yr after left pneumonectomy. Functional compensation for gas exchange in these dogs arose from adjustment of existing structures in the remaining lung including an increased capillary blood volume, enlargement of alveolar air spaces, and thinning of the alveolar-capillary membrane barrier, which in turn led to a modest increase in the surface area for diffusion and a reduction in the resistance of the membrane to diffusion. These "passive" structural changes, coupled with an enhanced exercise-induced polycythemic response and augmented pulmonary capillary recruitment, were sufficient to meet the functional demand; consequently exercise performance was not appreciably impaired by left pneumonectomy even in the face of an apparent diffusion limitation at heavy exercise (4).

Since the left lung is smaller than the right (by 17-38\%), we hypothesized that after removal of the larger right lung, physiologic reserves in the remaining lung would be diminished and nonstructural adaptation may not be sufficient to meet the demands of heavy exercise. Indeed, exercise capacity was limited early ( $2 \mathrm{mo}$ ) after right pneumonectomy; ventilation-perfusion distribution was abnormal, pulmonary artery pressure was elevated and the recruitment of diffusing capacity for $\mathrm{O}_{2}$ was impaired, resulting in severe arterial $\mathrm{O}_{2}$ desaturation upon moderate exercise ( 8 ). However, by $12 \mathrm{mo}$ after right pneumonectomy, there had been significant improvements in all these parameters such that exercise performance was relatively well preserved compared with age- and sex-matched sham-operated controls ( 8 ). Studied by the same techniques, alveolar-arterial oxygen tension gradient and mean pulmonary artery pressure at a given level of oxygen uptake were significantly lower 1012 mo after right than after left pneumonectomy. In addition, physiologic measurements of lung diffusing capacity for carbon monoxide ( $\mathrm{DL}_{\mathrm{CO}}$ ) in these dogs during heavy exercise obtained by a rebreathing technique show that $\mathrm{DL}_{\mathrm{co}}$ at a given pulmonary blood flow is significantly higher after right than after left pneumonectomy (9). Therefore, the relative magnitude of functional compensation, per fraction of lung removed, was actually greater after right than after left pneumonectomy. This observation was unexpected, suggesting that additional sources of compensation were elicited after resection of the larger right lung that were not elicited after left pneumonectomy.

Tissue response to right pneumonectomy in adult dogs. The present morphometric results demonstrate that structural adaptation after right pneumonectomy is qualitatively and quantitatively different from that after left pneumonectomy and may vary in intensity with time after pneumonectomy. The consistent and global increase in volumes of septal structures at two time points after pneumonectomy supports a tissue "growth" response to right pneumonectomy. This increase is significant whether we analyzed the 5 and 16 mo postpneumonectomy data separately or together. At both times points, the increase in alveolar surface area was greater than that expected from the increase in tissue volume alone, suggesting the addition or increased complexity of alveolar septa. Whether this tissue response is due to cellular hyperplasia or hypertrophy cannot be answered from the present data. Volumes of all tissue compartments, particularly the interstitium, were higher at 5 than at 16 mo after pneumonectomy, consistent with heightened but 
transient cellular and extracellular metabolic activities during the first few months after pneumonectomy. Hypertrophic type II pneumocytes have been identified in rats after pneumonectomy (20). Since a balanced cell growth has been reported in rats after pneumonectomy (21), we might expect similar hypertrophic and proliferative changes in other parenchymal and nonparenchymal cells. There may be accumulation of fibroblasts, collagen, elastin, or other connective tissue elements, as well as margination of migratory cells in response to local or humoral factors released after pneumonectomy. In general, reparative lung growth involves initial accelerated hypertrophic or hyperplastic activities followed by structural remodeling (22). Early transient thickening of the alveolar septum and heightened metabolic activities of connective tissue have been reported in postpneumonectomy rats (23-26), but the time course of such changes has not been characterized in larger animals. One cannot rule out the possibility that reversible mild interstitial pulmonary edema developed initially after pneumonectomy; alternatively, an increased volume of the interstitial compartment may reflect impaired lymphatic drainage after pneumonectomy. Little information is presently available on adaptation of the lymphatic system to lung resection. Doerschuk and Sekhon (27) found in postpneumonectomy rats that the increase in interstitial fluid cannot account for the increased weight of the remaining lung. In our case, edema alone is unlikely to explain the persistently elevated tissue volumes at 16 mo after pneumonectomy when septal thickness had returned to normal.

Compensation in diffusing capacity for $\mathrm{O}_{2}$. The lack of a significant compensatory increase in morphometric $\mathrm{DL}_{\mathrm{O}_{2}}$ or its components at $\mathbf{5}$ mo after pneumonectomy is related to a lower hematocrit and a greater harmonic mean thickness of the tissueplasma barrier. Both factors increase the mean diffusion path of oxygen. In our previously reported dogs after left pneumonectomy, morphometric hematocrit was also lower than normal (3). This relative anemia is most likely related to the presence of indwelling cardiac catheters. In addition, a lower hematocrit leads to a lower estimate of $\Theta_{\mathrm{O}_{2}}$ according to Eq. 4 and, when combined with a slightly smaller increase in capillary blood volume, results in a lower $\mathrm{De}_{\mathrm{O}_{2}}$ and $\mathrm{DL}_{\mathrm{O}_{2}}$ at 5 mo after pneumonectomy than expected from estimates of structural changes alone.

In the three dogs 16 mo after right pneumonectomy, there was a significant compensatory increase in $\mathrm{DL}_{\mathrm{O}_{2}}$, associated with increases in $\mathrm{O}_{2}$ conductance of both the erythrocyte and membrane-plasma components, although only the former reached statistical significance. Pulmonary capillary blood volume also increased above that in the corresponding lung of control animals. These morphometric changes are consistent with physiologic measurements of $\mathrm{DL}_{\mathrm{co}}$, diffusing capacity of the membrane, as well as capillary blood volume at heavy exercise in these dogs after right pneumonectomy (9). The magnitude of postpneumonectomy compensation in $\mathrm{DL}_{\mathrm{O}_{2}}$ estimated by morphometry ( $33 \%$ above the corresponding control lung) is similar to that reported previously in dogs after left pneumonectomy (3), but the sources of compensation are different. In the present dogs, enlargement of alveolar air spaces after pneumonectomy was not prominent. Alveolar and capillary surface areas were significantly increased; mean thickness of the diffusion barrier was not reduced. The increase in $\mathrm{DL}_{\mathrm{O}_{2}}$ was entirely due to increases in capillary blood volume and the amount of gas exchange tissue. There is a good correlation between physiologic and morphometric estimates of diffusing capacity; in the group after right pneumonectomy, the relative reduction of morphometric $\mathrm{DL}_{\mathrm{O}_{2}}$ (36\% below both lungs of control animals) is similar to the relative reduction of physiologic $\mathrm{DL}_{\mathrm{co}}(31 \%)$ measured at peak exercise in the same animals (9).

In summary, these morphometric results confirm our interpretation of previous physiological observations $(7,8)$ and demonstrate for the first time that the adult dog lung is capable of postpneumonectomy compensatory growth, but this tissue response requires a stronger stimulus, i.e., the resection of $>50 \%$ of lung, than in immature animals. Why the response to left and right pneumonectomy should be different is an intriguing question that we cannot fully explain. What is called "adaptive response" after lung resection has two phases: (a) enlargement of the lung and alveolar air spaces to fill the chest cavity; and (b) tissue and capillary proliferation which adds septa to the enlarged air spaces. The latter proliferative response is further marked by initial cell hypertrophy and division followed by structural remodeling that eventually return the volume and surface densities of alveolar structures to normal. Alveolar enlargement would be apparent only if $(a)$ is not followed by $(b)$. It appears that the response to left pneumonectomy is limited to $(a)$ whereas $(b)$ occurs after the more extensive right pneumonectomy. Presumably the intensity of adaptive response needs to be greater after right than left pneumonectomy. The initiation of tissue growth response in the adult dog may require a higher threshold of stimulation (e.g., a greater alveolar-capillary stretch, higher pulmonary blood flow, or larger concentration of humoral or local stimulant substances) than in the immature dog, and may not be induced until other physiologic sources of adaptation prove inadequate for functional compensation. Ultimate structural compensation is incomplete as the absolute volume and surface area of alveolar tissue components remain significantly below normal (i.e., 70-80\% of corresponding values in both lungs of controls); capillary volume and surface area also remain reduced at $65-70 \%$ of normal. These longterm structural changes after right pneumonectomy are associated with a significant, albeit incomplete compensation in diffusing capacity of the remaining lung for oxygen.

\section{Acknowledgments}

The authors thank Debra M. Cloyd and the staff of the Animal Resources Center for their technical assistance.

This work was supported by the National Heart Lung and Blood Institute (R01-HL-40070) and by the Swiss National Science Foundation. Luis F. Herazo was supported by a National Heart Lung and Blood Institute Training grant (TL-07362). This work was done during the tenure of an Established Investigatorship from the American Heart Association to C. C. W. Hsia.

\section{References}

1. Thurlbeck, W. M., W. Galaugher, and J. Mathers. 1981. Adaptive response to pneumonectomy in puppies. Thorax. 36:424-427.

2. Davies, P., J. McBride, G. F. Murray, B. R. Wilcox, J. A. Shallal, and L. Reid. 1982. Structural changes in the canine lung and pulmonary arteries after pneumonectomy. J. Appl. Physiol. 53:859-864.

3. Hsia, C. C. W., F. Fryder-Doffey, R. C. Reynolds, R. L. Johnson, Jr., and E. R. Weibel. 1993. Structural changes underlying compensatory increase of diffusing capacity after left pneumonectomy in adult dogs. J. Clin. Invest. 92:758764.

4. Hsia, C. C. W., J. I. Carlin, P. D. Wagner, S. S. Cassidy, and R. L. Johnson, Jr. 1990. Gas exchange abnormalities after pneumonectomy in conditioned foxhounds. J. Appl. Physiol. 68:94-104. 
5. Hsia, C. C. W., J. I. Carlin, S. S. Cassidy, M. Ramanathan, and R. L. Johnson, Jr. 1990. Hemodynamic changes after pneumonectomy in the exercising foxhound. J. Appl. Physiol. 69:51-57.

6. Carlin, J. I., C. C. W. Hsia, S. S. Cassidy, M. Ramanathan, P. S. Clifford, and R. L. Johnson, Jr. 1991. Recruitment of lung diffusing capacity with exercise before and after pneumonectomy in dogs. J. Appl. Physiol. 70:135-142.

7. Hsia, C. C. W., L. F. Herazo, and R. L. Johnson, Jr. 1992. Cardiopulmonary adaptations to pneumonectomy in dogs. I. Maximal exercise performance. J. Appl. Physiol. 73:362-367.

8. Hsia, C. C. W., L. F. Herazo, M. Ramanathan, R. L. Johnson, Jr., and P. D. Wagner. 1993. Cardiopulmonary adaptations to pneumonectomy in dogs. II. Ventilation-perfusion relationships and microvascular recruitment. J. Appl. Physiol. 74:1299-1309.

9. Hsia, C. C. W., L. F. Herazo, M. Ramanathan, and R. L. Johnson, Jr. 1994. Cardiopulmonary adaptations to pneumonectomy in dogs. IV. Total diffusing capacity, membrane diffusing capacity and capillary blood volume. J. Appl. Physiol. In press.

10. Hsia, C. C. W., L. F. Herazo, M. Ramanathan, H. Claassen, F. FryderDoffey, H. Hoppeler, and R. L. Johnson, Jr. 1994. Cardiopulmonary adaptations to pneumonectomy in dogs. III. Ventilatory power requirements and muscle structural changes. J. Appl. Physiol. 76(5):2191-2198.

11. Weibel, E. R. 1984. Morphometric and stereological methods in respiratory physiology, including fixation techniques. In Techniques in the Life Sciences, Respiratory Physiology. A. B. Otis, editor. Elsevier, Ireland. 1-35.

12. Michel, R. P., and L. M. Cruz-Orive. 1988. Application of the Cavalieri principle and vertical sections method to lung: estimation of volume and pleural surface area. J. Microsc. 150:117-136.

13. Weibel, E. R., W. J. Federspiel, F. Fryder-Doffey, C. C. W. Hsia, M. Konig, V. Stalder-Navarro, and R. Vock. 1993. Morphometric model for pulmonary diffusing capacity. I. Membrane diffusing capacity. Respir. Physiol. 93:125149.

14. Weibel, E. R. 1970. Morphometric estimation of pulmonary diffusion capacity. I. Model and method. Respir. Physiol. 11:54-75.

15. Weibel, E. R., L. B. Marques, M. Constantinopol, F. Doffey, P. Gehr, and C. R. Taylor. 1987. Adaptive variation in the mammalian respiratory system in relation to energetic demand. VI. The pulmonary gas exchanger. Respir. Physiol. 69:81-100.

16. Holland, R. A., H. Shibata, P. Scheid, and J. Piiper. 1985. Kinetics of $\mathrm{O}_{2}$ uptake and release by red cells in stopped-flow apparatus: effects of unstirred layer. Respir. Physiol. 59:71-91.

17. Massion, W. H., D. R. Caldwell, N. A. Early, and J. A. Schilling. 1962. The relationship of dry lung weights to pulmonary function in dogs and humans. J. Surg. Res. 2:287-292.

18. Rahn, H., and B. B. Ross. 1957. Bronchial tree casts, lobe weights and anatomical dead space measurements in the dog's lung. J. Appl. Physiol. 10:154157.

19. Rahn, H., P. Sadoul, L. E. Farhi, and J. Shapiro. 1956. Distribution of ventilation and perfusion in the lobes of the dog's lung in the supine and erect position. J. Appl. Physiol. 8:417-426.

20. Uhal, B. D., and M. D. Etter. 1993. Type II pneumocyte hypertrophy without activation of surfactant biosynthesis after partial pneumonectomy. Am. J. Physiol. 264(Lung Cell. Mol. Physiol. 8):L153-L159.

21. Cagle, P. T., C. Langston, J. C. Goodman, and W. M. Thurlbeck. 1990. Autoradiographic assessment of the sequence of cellular proliferation in postpneumonectomy lung growth. Am. J. Respir. Cell Mol. Biol. 3:153-158.

22. Rennard, S. I., P. B. Bitterman, and R. G. Crystal. 1983. Response of the lower respiratory tract to injury. Chest. 84:735-739.

23. Burri, P. H., H. B. Pfrunder, and L. C. Berger. 1982. Reactive changes in pulmonary parenchyma after bilobectomy: a scanning electron microscopic investigation. Exp. Lung Res. 4:11-28.

24. Berger, L. C., and P. H. Burri. 1985. Timing of the quantitative recovery in the regenerating rat lung. Am. Rev. Respir. Dis. 132:777-783.

25. Brody, J. S., R. Burki, and N. Kaplan. 1978. Deoxyribonucleic acid synthesis in lung cells during compensatory lung growth after pneumonectomy. Am. Rev. Respir. Dis. 117:307-316.

26. Rannels, D. E., J. L. Addison, and R. A. Bennett. 1986. Increased pulmonary uptake of exogenous polyamines after unilateral pneumonectomy. Am. J. Physiol. 250(Endocrinol. Metab. 13):E435-E440.

27. Doerschuk, C. M., and H. S. Sekhon. 1990. Pulmonary blood volume and edema in postpneumonectomy lung growth in rats. J. Appl. Physiol. 69:11781182 